\title{
La atención a la diversidad desde la escuela primaria
}

\author{
The attention to the diversity from the primary school
}

Annie Yusleidys Quesada González ${ }^{1}$

Yusleidys Rodríguez Aguilar ${ }^{2}$

\section{Resumen}

Actualmente en Cuba se desarrolla la Tercera Revolución Educacional, etapa de perfeccionamiento superior a la etapa anterior, la que ha sido el resultado de las diversas investigaciones y aportes realizados por investigadores cubanos a todo lo largo y ancho del país. Como elemento particular para cada etapa ha predominado un enfoque educativo basado en las ideas de nuestro Héroe Nacional José Martí, combinado por el carácter humanista que se le concede a la educación. Con ello, se perfeccionan todos los sistemas educativos, en el que la Educación Primaria es la base para el aprendizaje de todos los educandos. El propósito fundamental es ofrecer una educación de calidad a la diversidad, condicionado por las estrategias que se diseñen a partir de los resultados del diagnóstico integral. De aquí la importancia de esta investigación que se traza como objetivo ofrecer sugerencias didácticas acerca de cómo enseñar a leer y escribir atendiendo las diferencias individuales de cada uno de los educandos con y sin necesidades educativas especiales que asisten a un mismo grupo clase.

Palabras clave: educación, aprendizaje, atención a la diversidad

\section{Abstract}

At the moment in Cuba the Third Educational Revolution, stage of superior improvement to the stage previous one is developed, the one that has been the result of the diverse investigations and contributions carried out by Cuban investigators to all the long and wide of the country. As particular element for each stage an educational focus based on our National Hero's ideas José Martí has prevailed, combined by the humanist character that is granted to the education.

Recibido: 6 de julio de 2020 Aceptado: 2 de diciembre de $2020 \sim$ Publicado: 1 de enero de 2021

${ }^{1}$ Doctora en Ciencias Pedagógicas. Licenciada en Educación en la especialidad Educación Primaria. Docente e investigadora del Departamento de Educación Primaria de la Universidad de Granma (UDG) Granma, Cuba. Correo electrónico: aquesadag@udg.co.cu

${ }^{2}$ Doctora en Ciencias Pedagógicas. Licenciada en Educación en la especialidad Educación Especial. Docente e investigadora del Departamento de Educación Especial de la Universidad de Granma (UDG) Granma, Cuba. Correo electrónico: yrodrigueza@udg.co.cu 
With it, all the educational systems are perfected, in which the Primary Education is the base for the learning of all the students. The fundamental purpose is to offer an education of quality to the diversity, conditioned by the strategies that are designed starting from the results of the integral diagnosis. Of here the importance of this investigation that is traced as objective to offer didactic suggestions about how to teach to read and to write assisting the individual differences of each one of the students with and without special educational necessities that attend one group class.

Keywords: education, learning, attention to the diversity

\section{Introducción}

El proceso de Perfeccionamiento del Sistema Nacional de Educación ha transitado por diferentes etapas, cada una superior a la anterior, y constituye un proceso inacabable y permanente que consecutivamente ofrece nuevas y más complejas tareas de la pedagogía, la ciencia y la técnica. La calidad de la educación que se imparte en todos los niveles de enseñanza, la atención a las diferencias individuales que tenemos en nuestras aulas y con ello, la preparación del docente, constituyen eslabones fundamentales en este nuevo proceso de perfeccionamiento.

La atención a las diferencias individuales se garantiza como principio de la educación cubana, para lo cual se enmarca el carácter preventivo que la misma tiene. El docente a través de la clase debe atenderlas en todos los momentos. Para ello, ha de partir de conocer las características de sus educandos a profundidad, así como las de su entorno familiar y social. Dicho conocimiento le permitirá prevenir, corregir y/o compensar las carencias a corto, mediano o largo plazo, que el educando pueda presentar.

Vasto es el arsenal de conocimientos que poseen los docentes de la Educación Primaria a través de su práctica pedagógica, entre los que se destacan: Quesada Ramírez, C. (2010); Pérez Torres, S. (2012); Quesada González, A. (2014); Cedeño Gamboa, F. (2014); Fonseca Sanz, A. (2017). Coinciden al afirmar que un gran número de educandos con un coeficiente de inteligencia medio tienen dificultades en el aprendizaje, y se acentúa en aquellos que poseen un coeficiente por debajo de la media; por lo que se pueden notar en un grupo clase variadas limitaciones en el aprendizaje de los educandos.

La experiencia de las autoras de la investigación como maestras de las Educaciones Primaria y Especial, en primer lugar, y como profesoras de los Departamentos de Educación Primaria y Educación Especial de la Universidad de Granma, les ha permitido apreciar la problemática objeto de investigación mediante 
diversas observaciones a clases de Lengua Española, encuestas, entrevistas a docentes y directivos, pruebas pedagógicas a educandos de diferentes grados y ciclos, en entrenamientos e inspecciones realizadas a las escuelas primarias del territorio, así como en actividades metodológicas efectuadas. Dentro de las limitaciones que se manifiestan con más frecuencia en los educandos son las relacionadas con la lectura, la escritura, la comprensión y la construcción de textos orales y escritos.

Para mitigar dichas limitaciones, es de insoslayable valor para el docente primario enriquecer sus conocimientos, habilidades, capacidades y actitudes hacia la diversidad, todo lo cual le permitirá tener disponible los recursos metodológicos para su preparación, dígase creatividad en los métodos, medios de enseñanza, procedimientos utilizables, formas de evaluación, entre otros, para que exista un aprendizaje eficaz, con calidad, por parte del educando. La actitud del docente es fundamental en el proceso de atención a la diversidad.

Cada educando es un ser único e irrepetible, un desafío para el docente que lo educa e instruye en las diferentes enseñanzas que se cursan, una tarea ardua, pero no imposible. La práctica educativa ha demostrado que no todos los docentes de la Educación Primaria poseen los mecanismos necesarios para ofrecer una educación de calidad a la diversidad, lo que está provocado por diversas causas, entre las que se pueden señalar:

-insuficiente conocimiento de las particularidades de los educandos con necesidades educativas especiales (NEE),

-insuficiente dominio de técnicas y herramientas que se pueden emplear en el proceso de enseñanza-aprendizaje,

- rechazo a las diferencias, entre otras.

Estudios realizados demuestran que la generalidad de los educandos no leen por placer, sino porque es una exigencia en las diferentes asignaturas del currículo, lo que afecta directamente la comprensión de lo leído y consecuentemente, la construcción de textos. Dicho de otro modo, en muchos hogares no se incentiva el gusto y respeto por la buena lectura que los prepare a leer para aprender y a leer para leer.

Vale la pena aclarar que el educando debe ser un lector activo frente a la trama del texto que estudia para que sea capaz de:

- leer para aprender: esto requiere que interactúe con el texto, lo analice, lo interprete, se sienta un personaje más, lo reconstruya, utilice la intertextualidad; -leer para leer: incluye habilidades para "leer" las imágenes, gráficos, esquemas e ilustraciones que el texto pueda presentar, aprender a disfrutar de la lectura, a respetarla, a utilizar las estrategias (previas a la lectura en sí, durante esta y después 
de ella), las que favorecen de manera especial la comprensión del texto. Solo puede ser posible si el docente es un ejemplo de lector que disfruta el propio acto de una lectura amena, expresiva.

Las tendencias pedagógicas aseveran poner en el centro del proceso de enseñanza-aprendizaje al educando y a las intenciones de lograr un proceso formativo integrador que desarrolle al máximo sus potencialidades y que atienda y respete la diversidad, lo que estará basado en la formación de valores y lograr su inserción a la sociedad. De aquí la importancia de esta investigación que está dirigida a ofrecer sugerencias didácticas acerca de cómo enseñar a leer y escribir atendiendo las diferencias individuales de cada uno de los educandos que asisten a un mismo grupo clase.

\section{I. ¿Cómo atender, desde nuestras aulas, los educandos con y sin NEE asociadas o no a discapacidades?}

La Educación Especial sentó las bases para guiar a los docentes y personal capacitados a atender los educandos con NEE asociadas o no a discapacidades desde cualquier enseñanza. La educación, en Cuba, no discrimina ningún educando por su raza, nacionalidad, sexo, edad, diversidad intelectual, discapacidad, conducta familiar, género o religión, lugar de residencia, mediante una enseñanza desarrolladora, diferenciadora, con un profundo carácter científico y humanista.

Hoy la política educacional cubana se enfrasca para que los docentes de la Educación Primaria estén capacitados para atender a los educandos con y sin NEE, para que tengan la misma igualdad de oportunidades y fomentar en ellos actitudes y valores, así como brindar apoyo a la familia y la comunidad de manera lógica y coherente, para que sea unísona la labor que se acometa. Los educandos pasan la mayor parte del día en las aulas; por ello, se precisa la colaboración docenteeducando-padre para llevar adelante la educación sin tener barreras de aprendizaje.

Al respecto Barton, L. (1996), sociólogo experto en inclusión, define las barreras del aprendizaje de la siguiente manera:

Las barreras del aprendizaje aparecen a través de una interacción entre los educandos y sus contextos; la gente, las políticas, las instituciones, las culturas y las circunstancias sociales y económicas que afectan sus vidas. Consecuentemente la inclusión implica identificar y minimizar las barreras del aprendizaje y la participación y maximizar los recursos que apoyen ambos procesos.... las barreras, al igual que los recursos para reducirlas, se 
pueden encontrar en todos los aspectos y estructuras del sistema: dentro de los centros educativos, en la comunidad, en las políticas locales y nacionales. Las barreras pueden impedir el acceso al centro educativo o limitar la participación en él (p. 20).

Para una minoría de docentes, incluir en las aulas a educandos con NEE asociadas o no a discapacidades disminuye la calidad de la docencia que se ofrece al resto de los educandos del grupo clase. Este planteamiento resulta contradictorio: al trabajar en favor de los educandos con NEE asociadas o no a discapacidades se benefician todos los educandos, con un derecho por igual a la educación con la calidad que se requiere, con la participación activa de cada uno e igualdad de oportunidades. O sea que se identifican algunas habilidades que se puedan presentar en el proceso de enseñanza-aprendizaje y se eliminan barreras que, en muchos casos enfrentan, para acceder a su aprendizaje y su participación.

Esto permitirá su inclusión para la vida, porque:

El educando con necesidades educativas especiales, es un niño, adolescente o joven que posee características especiales en su desarrollo, que requieren de más ayuda que el resto de sus coetáneos dirigida con mayor intencionalidad y precisión a la solución de los problemas específicos, es decir precisan de apoyos dirigidos a satisfacer sus necesidades, las cuales pueden tener mayor o menor nivel de complejidad. Guerra Iglesias, S. (2013).

Autores nacionales y foráneos (Bell Rodríguez, R. (1998), Jiménez, P. (2001) y Pérez Cabaní, M. L. (2003); entre otros, han hecho referencia al trabajo de atención a la diversidad en diferentes momentos, aspectos estos de gran valor para todos aquellos que trabajen con la diversidad. Educar en la diversidad es una tarea difícil, se dirige a resolver el problema del acceso de todos a la educación por igual, para fomentar las capacidades en la totalidad de los seres humanos, independientemente de las diferencias que hacen única e irrepetible a cada persona.

Al respecto Silva, S. (2007), en su libro Atención a la diversidad. Necesidades educativas: Guía de atención para el docente de España, señala que la diversidad nace ante la necesidad de dar respuesta a una educación adaptada a las características y necesidades de los alumnos que por razones físicas, psíquicas, sensoriales y sociales no pueden seguir el ritmo normal del resto del grupo.

La atención a la diversidad, en Cuba, significa atender la diversidad de necesidades educativas especiales de todos y cada uno de los educandos en sus diferentes contextos de actuación. La escuela tiene como misión educar el buen gusto de los niños, adolescentes y jóvenes con NEE, desarrollar en ellos la capacidad de sentir la belleza de la naturaleza, sentirse parte de ella, de la vida social y cultural, 
por lo que el docente debe trasmitirle conductas, buenas costumbres, para con ello lograr su inclusión a la sociedad en que vive.

Las autoras coinciden con Guerra Iglesias, S. (2014) respecto a que:

La atención a la diversidad del alumnado, en las prácticas inclusivas, tiene gran importancia para la realización sistemática y articulada de acciones proactivas para su logro, ente las cuales resaltan promover la superación, el intercambio y la preparación docente, priorizar en la organización e higiene de la actividad docente una oferta de apoyos sociopsicopedagógicos y recursos didáctico-metodológicos para atender las necesidades educativas en diferentes contextos educativos (p.109).

Para Pujolás Maset, P. (2001), se entiende por necesidades educativas lo que toda persona necesita para acceder a los conocimientos, las habilidades, las aptitudes y las actitudes socialmente consideradas básicas para su integración activa en el entorno al que pertenece, como persona adulta y autónoma (p.26). Además plantea que el término necesidades educativas especiales es amplio e incluye no solo a los alumnos con alguna discapacidad o deficiencia, sino a todos aquellos que no se benefician, por el motivo que sea, de la enseñanza escolar, que el reto está en encontrar la manera de atender la heterogeneidad, de conseguir que aprendan juntos y hasta el máximo de sus posibilidades, alumnos diferentes, más que organizar la homogeneidad, de conseguir que aprendan juntos, y hasta el máximo de sus posibilidades, alumnos diferentes, más que organizar la homogeneidad, de encontrar los criterios que no permitan separarlos "justamente" (p.51). ... todo el mundo tiene necesidades educativas; que no sería necesaria la educación si las personas no tuvieran necesidades educativas. Señala además que hay personas que tienen necesidades educativas especiales, ya que para progresar hacia la autonomía personal y su integración social, necesitan temporalmente o de forma permanente, un conjunto de recursos y medios que no necesita el resto de la población y que habitualmente las escuelas no disponen de ellos (p.43).

La psicóloga Castellanos Simons, D. (2002) expresa al respecto ...Cualquier maestro tiene que trabajar en el aula con diferentes niveles de capacidad, con ritmos y estilos de aprendizaje disímiles, con necesidades, intereses y motivaciones muy singulares, así como con estudiantes que provienen de medios socioeconómicos y culturales muy distintos.

En los momentos actuales no se concibe una educación de calidad que no tenga en cuenta los procesos que benefician la atención a la diversidad, dígase intereses, capacidades, motivaciones, modos de actuación. En nuestras aulas no todos los educandos aprenden a la misma vez ni al mismo ritmo de trabajo. Los 
docentes deben estimular la participación en clases de los educandos con dificultades en el aprendizaje, atender con más perseverancia sus inquietudes, estados de ánimos (su silencio, su agresividad, su timidez) en un momento dado, hacer de la tarea que se orienta un ejercicio de creación e investigación, atendiendo las diferencias individuales, y con ello, la atención a la diversidad.

\section{Principales referentes teóricos que sustentan la comprensión y construcción de textos}

Para entender el proceso de comprensión y construcción de textos, es necesario partir del concepto texto planteado por lingüistas e investigadores.

Bernárdez, E. (1982) lo explica como:

La unidad lingüística comunicativa fundamental, producto de la actividad verbal humana, que posee siempre un carácter social; está caracterizado por un cierre semántico y comunicativo, así como por su coherencia profunda y superficial, debido a la intención comunicativa del hablante de crear un texto íntegro, y a su estructuración mediante dos conjuntos de reglas: las propias del nivel textual y las del sistema de la lengua.

En esta definición se enuncian elementos claves a tener en cuenta durante la comprensión: contexto de producción del texto, coherencia semántica y sintáctica y las reglas de estructuración del texto.

La Dra. Roméu, A. (1999), por su parte, lo define como:

Un enunciado comunicativo coherente, portador de un significado; que cumple una función comunicativa en su contexto específico y se produce con una determinada intención comunicativa, por lo cual el emisor se vale de distintos procedimientos y escoge los medios lingüísticos más adecuados.

Esta definición tiene en cuenta elementos pragmáticos que el lector debe descubrir durante la comprensión: contexto, intención comunicativa; así como los rasgos lingüísticos que caracterizan el texto.

En sentido general, puede afirmarse que las definiciones citadas poseen puntos de coincidencia al presentar al texto con elementos de la Semiótica, la Semántica, la Pragmática, la Sociología, la Lingüística y la comunicación.

Teniendo en cuenta los nuevos enfoques para definir el concepto texto, se han producido cambios en las maneras de abordar el proceso de comprensión de textos. Parodi, G. (2005) lo considera como:

Un proceso cognitivo, constructivo e intencionado en el que el lector elabora una interpretación y una representación mental de los significados textuales, basándose tanto en la información del texto escrito como en sus conocimientos previos y de acuerdo con un objetivo de lectura acorde con sus propósitos y las 
demandas del medio social.

Hernández, J. (2010) lo define como:

Un proceso complejo, sistémico y organizado, dirigido a elaborar los significados de los textos, fundamentar los juicios obtenidos y valorar la significación socialmente positiva que tienen para el contexto de actuación del lector, mediante la aplicación de múltiples relaciones cognitivo-afectivas entre el lector, el texto y el contexto sociocultural, con el fin de favorecer su formación más plena.

Las autoras de esta investigación asumen las definiciones antes mencionadas y enfatizan que el proceso de comprensión implica múltiples y complejos procesos. El lector actualiza el potencial semántico contenido en el texto, realiza la decodificación semántico-pragmática sobre una base de actualización determinada y decodifica los diálogos que el autor ha establecido con el texto creado y el que establece el propio texto con él mismo.

Es importante puntualizar que el lector utiliza en el acto de lectura sus esquemas y conocimientos previos, realiza las inferencias necesarias y aplica, amplía y enriquece sus conocimientos de vocabulario. En otras palabras, comprende lo que lee según su estadio de desarrollo cognitivo y los vínculos afectivos y motivacionales que posea.

El estudio de los aspectos gnoseológicos de la lectura permite apreciar su significación social, educativa y práctica. Desde el punto de vista social, se adquieren conocimientos técnico-culturales, históricos, políticos y económicos, siempre teniendo presente el grado escolar que cursa el educando. En el plano educativo, su análisis de las finalidades y actitudes de los autores, los valores y mensajes positivos y negativos de las lecturas que se estudian y otras fuentes de información favorecen la formación de cualidades necesarias en él. En el aspecto práctico, leer las distintas obras escritas por autores de diversos países de habla hispana o traducidas al español, permite el beneficio del tiempo y brinda la ventaja de comprender la información tal como la expresa el autor.

Según Vigotsky, el acto lector resulta complejo, pues exige de un alto nivel de abstracción y comienza en momentos en que las funciones necesarias para que se lleve a cabo de forma plena no han completado su desarrollo, si bien diferentes autores centran su atención, ya sea en los procesos de decodificación o en los de comprensión, la mayoría de los que han profundizado en el problema del aprendizaje de la lectura, están de acuerdo en afirmar que los dos tipos de procesos son necesarios y que se influyen mutuamente.

En la enseñanza-aprendizaje de la comprensión de textos escritos, en una primera etapa, el docente va a dirigir personalmente la comprensión del mismo y paulatinamente, el educando adquiere un mayor compromiso particular a la hora de 
reconstruirlos, de esta manera, el docente jugará un papel secundario.

$\mathrm{Al}$ estudiar el proceso de la comprensión de textos escritos, se deben tener en cuenta las dimensiones que conforman la trama del texto: el significado (semántica), la estructura que adopta (sintaxis) y el contexto sociocultural (pragmática). La dimensión sintáctica se establece primero, aun cuando la semántica y el discurso pueden prevalecer. (Graesser y otros en: Van Dijk, 2000). La dimensión sintáctica en el proceso de enseñanza-aprendizaje de la comprensión de textos escritos estudia la estructura de la oración y el modo en que se enlazan las palabras para formar oraciones con sentido. La dimensión semántica, por su parte, se refiere a lo que significa, el vocabulario. La dimensión pragmática, se propone integrar en el estudio del lenguaje la función que desempeñan los usuarios y las situaciones en las cuales se utiliza.

La relativa capacidad de un lector en el proceso de enseñanza-aprendizaje de la comprensión de textos escritos en particular, es notoriamente importante para el desarrollo exitoso del proceso, pero también lo es el propósito del lector, la cultura social, el conocimiento previo, el control lingüístico, las actitudes y los esquemas conceptuales. Toda lectura es interpretación y lo que el lector es capaz de comprender y de aprender a través de ella depende de lo que el lector conoce y cree antes de la lectura.

Las autoras de esta investigación plantean que los educandos logran transitar por los niveles de comprensión cuando exponen preguntas relacionadas con el texto que guían su lectura; son capaces de relacionar la información obtenida del texto con sus anteriores conocimientos sobre el tema que estudia; efectúan inferencias, expresan hipótesis y las ponen a prueba para ver si entienden todo lo que han leído, o si deciden retroceder en palabras, líneas o ideas para esclarecer sus dudas; comparten sus interpretaciones con otros lectores y explican sobre lo leído, captan una significación, pero al mismo tiempo están preparados para su reconstrucción.

Al referirnos al proceso de la escritura este aparece denominado de diferentes formas en las bibliografías consultadas: composición escrita, expresión escrita, redacción, construcción y producción textual. Por estas razones, sin importar la denominación utilizada, el elemento común de todas ellas es el reconocimiento que ocupa un lugar esencial entre los aspectos que alcanza el trabajo para el desarrollo del lenguaje.

La comprensión y la construcción de textos son procesos estratégicos. El educando se apropia de estrategias para procesar y construir textos, las que son el resultado de las que utiliza el docente. El proceso de construcción de textos precisa de la imaginación del educando, su creación, de conocimientos acerca del tema que estudia y de estrategias para escribir sobre el texto, y unido a ello, como elemento 
que no podemos olvidar, el contexto. Texto y contexto no pueden verse aislados, no puede existir uno sin el otro.

Según Baena, A. (1985) el sujeto comunicante construye una significación que es interpretada por el receptor o destinatario. La significación es una construcción humana que se inició desde que el hombre aprendió a hablar y aún continúa realizándola.

La construcción de textos escritos, eslabón culminante de la enseñanza de la expresión escrita, resulta una tarea compleja en los educandos de diferentes niveles de enseñanza, porque su basamento se justifica en aspectos que se relacionan con construir y organizar ideas relacionadas con el texto que se estudia. Por ende, es necesario que el educando, durante su aprendizaje, comprenda que la construcción de textos es una herramienta que le va a servir para toda la vida, que le proporcionará comunicarse con sus coetáneos, expresarse por escrito con precisión, fluidez, exponiendo sus sentimientos de manera ordenada, expresados de manera gráfica con un correcto lenguaje. Ya José Martí lo aseveró cuando dijo: "Saber leer es saber andar; saber escribir es saber ascender".

\section{III. ¿Qué hacer para atender las diferencias individuales y con ello, la atención a la diversidad de educandos?}

La atención a la diversidad no implica una atención personalizada excluyente de la atención a la persona dentro de un colectivo. Implica reconocer a cada persona como miembro de un grupo, respetar la dimensión personal, pero no al margen de la dimensión social (yo soy yo, pero soy contigo) Cobas, C. (2005).

El docente tiene la responsabilidad de darle solución a esta problemática y con ello lograr la inserción de este educando a su grupo evolutivo. Debe realizar un estudio profundo de las ciencias sociológicas, psicológicas y pedagógicas, para poseer herramientas que le permitan su mejor educación. Resumiendo, permitirá encontrar el mecanismo para brindar ayuda pedagógica y psicológica al educando con estas características.

No todos los educandos reaccionan de la misma manera ante las exigencias que para cada grado escolar están establecidas. En resultados obtenidos por docentes, investigadores y especialistas se observa la existencia de problemas lectores o de escritura que contribuyen de manera acelerada al fracaso escolar, la repitencia y lo que es peor, la desmotivación por el estudio en las diversas asignaturas del grado. Entre ellas están: la disgrafia, la dislexia y la discalculia, como dificultades de aprendizaje más frecuentes en las aulas. 
La disgrafia es un trastorno de la escritura que afecta a la forma o al significado, que se encuentra entre las alteraciones psicopedagógicas, incluidas dentro del efecto secundario, que puede estar asociado a diferentes patologías que presentan nuestros educandos o constituyendo una patología por sí sola. Esta puede ser disgrafia disléxica o disgrafia caligráfica.

La dislexia es el trastorno de la lectura relacionado con una lesión o desarrollo deficiente de algunos sectores de la corteza cerebral. Está relacionada con desviaciones generales del desarrollo del lenguaje oral y escrito. Son los trastornos en la identificación, reproducción, comprensión e interpretación de los signos hablados y escritos.

La discalculia es una dificultad específica en el proceso de aprendizaje del cálculo, que se observa entre los educandos de inteligencia normal, no repetidores de grados y que concurren normalmente a la escuela primaria pero realizan difícilmente una o varias operaciones matemáticas.

Los educandos con dificultades en el aprendizaje leen y escriben de manera más lenta que los educandos promedio. En consecuencia, prestan mayor atención a detalles secundarios en la ilustración de la lectura, como colores, figuras u otro aspecto relacionado con la misma, que a los sonidos o combinaciones sonoras y al contenido del discurso. Por consiguiente incide en la decodificación de la información que trasmite el texto o discurso que analiza, pues existe falta de atención y provoca que el proceso de lectura no sea exitoso, por tanto su comprensión será fragmentada, incompleta y consecuentemente la construcción de texto se verá limitada.

Así pues, si el educando que presenta dificultades en la lectura de textos, es al que, en su mayoría, el docente no le proporciona la posibilidad de leer frente a sus compañeros de aula, es al que las preguntas que se le realizan generalmente son reproductivas y las tareas asignadas son sencillas, el educando no tendrá necesidad de buscar herramientas que le permitan llegar a una zona de desarrollo potencial y se mantendrá rezagado ante el resto de sus compañeros.

Para enseñar a leer y escribir a educandos que presentan dificultades en el aprendizaje, es necesario el trabajo con las habilidades idiomáticas porque, en la mayoría de los casos, son limitadas. En no pocas ocasiones cuando están frente al proceso de lectura, en ellos se presenta la lectura silábica por mucho más tiempo que el esperado, cambios de sílabas en las letras, palabras o frases, omisiones de letras, adiciones, sustituciones, transposiciones (alteraciones en el orden de las letras o sílabas). También encontramos en su lectura la mezcla o trastornos de secuenciación de sílabas, contaminación (es la unión de dos palabras en una o dos 
sílabas en una), o la preservación (es la repetición de letras y sílabas). Realizan la lectura como si adivinaran el contenido de la misma.

No hay que olvidar que para lograr mejor resultado, los textos a leer deben ser sencillos, para que estén en correspondencia con sus habilidades idiomáticas. El énfasis es ver reflejado sus vivencias e intereses en el texto a estudiar. Si no se logra una lectura a profundidad, no puede ocurrir una buena comprensión y más tarde, la construcción del texto que se analiza.

$\mathrm{Su}$ expresión oral no constituye riesgo, pues el docente puede lograr que conteste preguntas relacionadas con la lectura. El éxito está en la utilización de variados métodos de enseñanza y procedimientos para llevar adelante esta labor de enseñar a todos, sin que existan barreras de aprendizaje. Es necesario combinar el método fónico-analítico-sintético con otros métodos como el método silábico o métodos globales, para obtener mejores resultados.

Vigotsky, L. (1982) destaca la importancia de dos momentos en la asimilación de los conocimientos: el plano interpersonal, interpsicológico, y, por tanto, social de la formación de las acciones mentales durante el desarrollo de la actividad humana, y el plano intrapersonal, intrapsicológico y, por ello, individual de la acción mental. Entre el punto de partida del primero y el término del segundo se sitúa lo que él llama la Zona de Desarrollo Próximo (ZDP).

La Zona de Desarrollo Próximo remite a la distancia que existe entre lo que el sujeto es capaz de hacer por sí solo y lo que puede alcanzar mediante la ayuda con otros en un espacio de interacción socialmente construido. Se puede plantear que la ZDP pone de manifiesto la colaboración del docente dentro de las metas del desarrollo interno hasta que el educando desarrolle el dominio consciente de su aprendizaje e inicia de esta manera un nuevo proceso de desarrollo con su propio desempeño. En esta zona tiene lugar el desarrollo del control hasta llegar a convertirse en autocontrol de los procesos de comprensión y construcción del texto.

En la atención a estos educandos, es importante su estudio para diagnosticar su desarrollo evolutivo, su zona de desarrollo actual y zona de desarrollo próximo, sus intereses, motivaciones, sus deseos de aprender con o sin ayuda de sus compañeros de aula, es decir, encontrar la pareja de equilibrio adecuada, que permita sentirse a gusto cuando necesite ayuda y se le brinde, sin sentirse burlado o por debajo de sus capacidades, por el contrario, es sentir esa ayuda necesaria para avanzar, poco a poco, en el ascenso al conocimiento deseado. La autoestima, sus estilos de aprendizaje, sus relaciones interpersonales, dentro y fuera de la escuela, así como la familiar y social, serán elementos indispensables a tomar de la mano por parte del docente para lograr su fin deseado: su inclusión a la sociedad.

No hay que olvidar que siempre que el texto se imagine como un medio de 
comunicación y el educando llegue a descifrarlo para extraer y expresar la información contenida en él, la lectura y comprensión del texto constituirá un mediador para el desarrollo del pensamiento conjuntamente con el lenguaje. La lectura comienza con un estímulo visual, y cuando ocurre la comprensión termina con el significado. Para todos es indudable que la actividad de lectura tiene en su base como motivo la búsqueda del significado y la mayoría reconoce que los conocimientos visual, ortográfico, fonológico, sintáctico, semántico, discursivo y del mundo en que vive el lector desempeñan un rol en este proceso.

$\mathrm{Al}$ respecto, las autoras son del criterio que la comprensión se transforma de un lector a otro. En cada lector, el proceso se puede dar de forma diferente, de una tarea a otra e incluso, dentro de un mismo texto pueden prevalecer las fuentes de información usadas, y se pueden transformar en el instante de unos pocos minutos de lectura. La transición por los niveles de comprensión de textos se logra cuando el lector expresa sus experiencias almacenadas, experiencias que aparecen en la medida que decodifica las palabras, frases, párrafos e ideas del autor del texto.

En otras palabras, el docente podrá acertadamente constatar si esta información ha sido decodificada de forma correcta, en la medida en que el educando desarrolle en el texto creado las unidades de lenguaje y de significado que surgen en el texto antes leído, siempre que lleve a cabo la comprensión y su transición por los niveles de manera exitosa.

Pero en los educandos con dificultades en el aprendizaje no sucede de la misma manera. La comprensión se hace limitada, por presentar un vocabulario escaso, limitado, esto da lugar a que los párrafos en las lecturas que se estudian sean vistos por ellos como una suma de oraciones, y no como la integridad del texto analizado. Es necesario inculcarles la lectura en silencio como motivación para obtener una mejor lectura oral que permitirá el dominio del tema que se trate, la correcta pronunciación, entonación de palabras y oraciones, y de ahí el ascenso a la comprensión del texto.

Sus dificultades están dadas, fundamentalmente, en la estructura léxicogramatical del lenguaje, limitada discriminación de los sonidos de los fonemas, del análisis y la síntesis sonora. Su mayor dificultad está, por lo tanto, en el lenguaje escrito a la hora de construir un texto.

En resumen podemos afirmar que la familia juega un papel fundamental en el desarrollo del educando; su papel es determinante en cuanto él puede progresar o retroceder, pues es en el hogar donde reafirma los contenidos recibidos en clases y realiza sus tareas de aprendizaje. Los padres juegan un rol determinante desde el hogar para dirigir el aprendizaje de su hijo, apoyarlos en los quehaceres encomendados desde la escuela y a tener confianza en sí mismo, solo así se sentirán 
seguros para abordar la lectura, comprensión y construcción de textos, ya sean orales o escritos.

\section{Conclusiones}

Los referentes teóricos utilizados permiten declarar que la comprensión y construcción de textos han sido abordados por diversos autores y han aportado elementos sustanciales a las investigaciones realizadas en diferentes contextos educativos.

El propósito fundamental del Perfeccionamiento del Sistema Nacional de Educación cubano es ofrecer una educación de calidad a la diversidad, condicionado por las estrategias que se diseñen a partir de los resultados del diagnóstico integral.

Para lograr una correcta comprensión y construcción del texto que se analiza, el docente debe dotar a sus educandos de herramientas necesarias para lograr una correcta lectura, con expresividad y fluidez, respetando las pausas y que permita el disfrute del texto en el intercambio con el autor del escrito.

\section{Referencias bibliográficas}

Baena, A. (1985). El lenguaje en relación con sus funciones esenciales en el proceso de adquisición del conocimiento y el proceso de comunicación. Colombia: (texto digitalizado).

Barton, L. (1996). Discapacidad y sociedad. Madrid: Morata.

Bernárdez, E. (1982). Introducción a la Lingüística del texto. Espasa-Calpe, Madrid.

Bell Rodríguez, R. (1997). Educación Especial: Razones, Visión Actual y Desafios. Editorial Pueblo y Educación. Ciudad de la Habana, p. 15 -19

Castellanos Simons, D.; Grueiro, I. (2002). Una reflexión sobre la inteligencia y su desarrollo. C E Educacionales ISP"EJV" S/e p.1.

Cedeño Gamboa, F. (2014). La prevención en la formación de habilidades para el aprendizaje ortográfico en el primer ciclo de la Educación primaria. (Tesis doctoral). Universidad de Granma. Cuba.

Cobas, C. (2005). Las adaptaciones curriculares. Su comprensión e implementación. Revista de Educación. Memorial José Martí.

Fonseca Sanz, A. (2017). Las tareas de aprendizaje en la comprensión de textos escritos en el quinto grado de la Educación Primaria. (Tesis doctoral). Universidad de Granma. Cuba.

Grellet, F. (1981). Developing Reading Skills. Great Britain: Cambridge University Press. 
Guerra Iglesias, S. (2013). Curso de didáctica en la Educación Especial. La Habana. Cuba. (En soporte digital).

(2014). Actualidad de la atención educativa a los niños y adolescentes con necesidades educativas especiales. Editorial Pueblo y Educación. La Habana. Cuba. Hernández, J. (1998). Estrategia metodológica para la construcción de significados en la comprensión de textos literarios en la E.G.M. (Tesis de maestría). Camagüey. Cuba.

Jiménez, P. (2001). De educación especial a educación en la diversidad. Archidona (Málaga): Aljibe, p. 15 - 19, 207 - 368.

MINED (2016). Documentos para el Perfeccionamiento del Sistema Nacional de Educación. Instituto Central de Ciencias Pedagógicas (ICCP). Cuba.

Parodi, G. (2005). La comprensión del discurso especializado escrito en ámbitos técnicoprofesionales, ¿Aprendiendo a partir del texto? Signos 38(50), 221-267, Valparaíso, Chile. Recuperado de http://www.scielo.cl.

Pérez Cabaní, M. L. (2001). Currículum y actividades de Enseñanza y aprendizaje. Departamento de Pedagogía. Universidad de Girona, p. 20 -24

Pérez Torres, S. (2012). Estrategia de superación para integrar la historia local al proceso de enseñanza aprendizaje de la Historia de Cuba en la Educación Primaria. (Tesis de maestría). Universidad de Ciencias Pedagógicas Blas Roca Calderío. Cuba.

Pujolás Maset, P. (2001). Atención a la diversidad y aprendizaje cooperativo en la educación obligatoria. (Málaga): Aljibe, p. 23 - 71

Quesada González, A. (2014). Modelo didáctico de transición por los niveles de comprensión de textos escritos en la asignatura Lengua Española para escolares del 2do. ciclo de la Educación Primaria. (Tesis doctoral). Universidad de Ciencias Pedagógicas Blas Roca Calderío. Cuba.

Quesada Ramírez, C. (2010). Modelo de organización pedagógica del proceso de producción de textos escritos para el segundo ciclo de la Educación Primaria. (Tesis doctoral). Universidad de Ciencias Pedagógicas Blas Roca Calderío. Cuba.

Silva, S. (2007). Atención a la diversidad. Necesidades educativas: Guía de actuación para docentes. España: Ideaspropias.

Van Dijk, T. (1983). La ciencia del texto. Barcelona: Ediciones Paidós.

Vigotsky, L. (1998). Pensamiento y Lenguaje. Editorial Pueblo y Educación. La Habana. Cuba. 